\title{
Low Body Mass Index as a Risk Factor for the Onset of Porosity of the Mandibular Bone in the Elderly
}

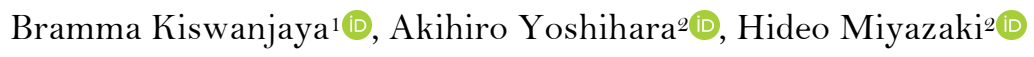

\begin{abstract}
'Department of Dentomaxillofacial Radiology, Faculty of Dentistry, Universitas Indonesia, Jakarta, Indonesia.
${ }^{2}$ Division of Preventive Dentistry, Department of Oral Health Science, Graduate School of Medical and Dental Sciences, Niigata University, Niigata, Japan.
\end{abstract}

Correspondence: Bramma Kiswanjaya, DDS, Ph.D., Department of Dentomaxillofacial Radiology, Faculty of Dentistry, Universitas Indonesia. E-mail: brammakiswanjaya@gmail.com

Academic Editor: Alessandro Leite Cavalcanti

Received: 23 January 2020 / Review: 18 July 2020 / Accepted: 13 September 2020

How to cite: Kiswanjaya B, Yoshihara A, Miyazaki H. Low body mass index as a risk factor for the onset of porosity of the
mandibular bone in the elderly. Pesqui Bras Odontopediatria Clín Integr. 2021; 21:e5900.
https://doi.org/10.1590/pboci.2021.052

\begin{abstract}
Objective: To investigate whether a low body mass index (BMI) has a significant relationship with mandibular bone porosity progression by conducting a mandibular inferior cortex (MIC) classification in elderly Japanese people. Material and Methods: A total of 266 study subjects, aged 70 at baseline, were recruited for this study, conducted from 1998 to 2007. The subjects were divided into two groups according to changes in the MIC on serial panoramic radiographs during this nine-year study period: a no change group (MIC-NC) and a change group (MIC-C). All subjects in the MIC-C showed changes trending toward greater fragility. We evaluated the BMI at baseline. Logistic regression analysis was performed to assess the relationship between the MIC condition during the nine-year period (0: MIC-NC, 1: MIC-C) and BMI $\left(\mathrm{kg} / \mathrm{m}^{2}\right)$ adjusted for gender, current health status (CHS), and smoking habit (SH) at baseline. Results: The mean and standard deviations of the BMI at baseline in the MIC-NC and MIC-C were $22.8 \pm 2.1$ and $21.8 \pm$ $2.5 \mathrm{~kg} / \mathrm{m}^{2}$ for males and $23.1 \pm 2.9$ and $21.9 \pm 2.4 \mathrm{~kg} / \mathrm{m}^{2}$ for females. There was a significant relationship between the MIC condition and the BMI in both males $(p=0.04)$ and females $(p=0.01)$. The logistic regression analysis revealed a significant association between the MIC condition over the nine-year period and the BMI $(\mathrm{OR}=0.84, \mathrm{p}=0.003)$, which was adjusted depending on the gender $(\mathrm{OR}=5.18, \mathrm{p}=0.000)$, CHS $(\mathrm{OR}=0.53, \mathrm{p}=0.015)$, and $\mathrm{SH}(\mathrm{OR}=4.15, \mathrm{p}=0.002)$ at baseline. Conclusion: A low BMI carries a risk of developing mandibular bone porosity by measuring the MIC condition in panoramic radiographs.
\end{abstract}

Keywords: Aging; Body Mass Index; Osteoporosis; Longitudinal Studies. 


\section{Introduction}

Osteoporosis and the fractures associated with it have become public health problems worldwide. Researchers have shown that the risk of osteoporosis or fragility fractures increases with advancing age in the elderly [1]. One out of three women and one out of five men aged 50 or above will suffer a fragility fracture in their remaining lifetime [2]. The problem becomes more difficult to overcome because of the characteristics of osteoporosis, which can occur before any symptoms become visible. It has been suggested in several studies that many women who sustain a fragility fracture are not appropriately diagnosed and treated for probable osteoporosis [3,4]. Further, osteoporotic fractures are associated with considerable morbidity, increase the risk of mortality, and indicate a significantly heightened risk of additional fractures. Therefore, it is necessary to investigate the risk factors for bones becoming porous to prevent fractures related to osteoporosis.

One of the risk factors for osteoporosis is body mass index (BMI). Many investigators have reported that a low BMI is an important risk factor for bone fragility, whereas being overweight or obese appears to protect against osteoporosis [5,6]. From a public health perspective, the situation becomes even more complicated because being overweight or obese is well documented as a risk factor for increased morbidity from diabetes, hypertension, and cardiovascular diseases and is also associated with increased mortality [7,8]. Although previous cross-sectional studies have investigated the relationship between the BMI and the local quality of mandibular bone, for example, in 136 elderly people aged 52-86 [9], it is necessary to conduct a longitudinal study that restricts the age of the subjects to include a larger number of healthy elderly males and females. This will facilitate the exploration of the risk factors for BMI as being related to mandibular bone porosity.

Many diagnostic instruments are available for assessing bone mineral density (BMD). Some use high levels of radiation, are relatively expensive, and are applied to confirm a diagnosis in patients with osteoporosis symptoms rather than screening healthy elderly people. Furthermore, those instruments are not often used routinely by dentists in their clinics. On the other hand, panoramic radiographs are frequently taken before or during dental procedures as diagnostic tools to examine teeth and jaws in general dental practice worldwide. Some researchers have suggested that mandibular inferior cortex (MIC) classification using panoramic radiographs, initially devised by Klemetti et al. [10], is effective in women who are at high risk for osteoporosis [11]. It was concluded in some recent studies that the MIC classification is reliable and that using dual-energy X-ray absorptiometry (DEXA) as a gold standard, it achieves a significant diagnostic accuracy in identifying postmenopausal women with a low BMD [12]. Previously, we demonstrated that MIC classification has a significant relationship with bone stiffness on the os calcis [13] and total serum calcium in the blood [14], as well as bone metabolic markers like serum bone-specific alkaline phosphatase as a bone formation marker and urinary N-telopeptide cross-links of type I collagen as a bone resorption marker [15]. Therefore, the MIC classification scheme can be considered to reflect bone loss during general bone metabolism. The purpose of this nine-year cohort study was to investigate whether a low BMI has a significant relationship with the progression of mandibular bone porosity in elderly people.

\section{Material and Methods}

Subject Sampling

The materials and methods of this study were described previously in other studies [13-15]. A baseline study was conducted in 1998, in which 4,542 citizens (2,099 men, 2,443 women), aged 70, registered in Niigata Prefecture, were sent a written request to participate in the survey. Of the 3,695 subjects who agreed 
to participate in the survey, and considering the availability of resources, 600 people were randomly selected with approximately the same number of males and females. Finally, a follow-up study took place in the ninth year. Of the 600 subjects, 27 did not provide information on their BMI and 272 dropped out. Seven people were excluded because they did not want to undergo dental panoramic radiography, and 28 pairs of radiographs were excluded because the images of the MIC were not qualified either at baseline or in the final year. Thus, a total of 266 subjects (136 men, 130 women) participated in this study. None of the subjects received any special nursing care during the study period. All subjects were healthy and living independently. The examination protocol used was reviewed and approved by the Ethics Committee of the Faculty of Dentistry, Niigata University.

Measurement of Mandibular Bone Porosity

To measure the mandibular bone porosity, we used the MIC on panoramic radiography. All panoramic radiographs were obtained using a Super Veraview X500 (Morita Co., Tokyo, Japan) at 5-10 mA for $15 \mathrm{~s}$, at a voltage of 60-80 kV. We used speed group 200 screens (HG-M and UR-2 film; Fuji Photo Film Co., Ltd., Tokyo, Japan). Measurement of the MIC classification was determined by observing the MIC distally from the mental foramen on one or both sides. If there was a different classification in porosity between the sides, the MIC classification was measured from the most severe classification. The results were divided into three groups (C1-C3) according to the method of Klemetti et al. [10] (Figure 1).
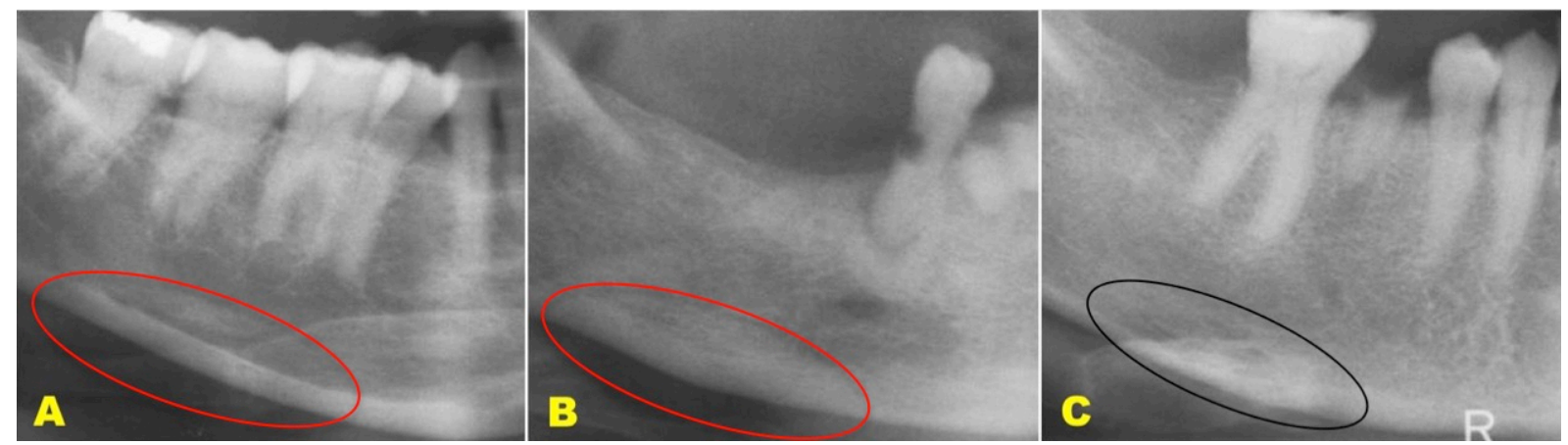

Figure 1. Mandibular inferior cortex classification on panoramic radiography. A. Normal cortex (C1): the endosteal margin of the MIC was smooth and even on both sides. B. Mildly to moderately eroded cortex (C2): the endosteal margin showed semi-lunar defects (lacunar resorption) with the formation of endosteal cortical residues, one to three layers thick on one or both sides. C. Severely eroded cortex (C3): the MIC is porous with dense endosteal residues on one or both sides.

To measure the condition of the MIC over the nine-year study period, the results of the MIC classification measurement were divided into two groups: those whose MIC classification did not change and those whose MIC classification changed from $\mathrm{MIC} \mathrm{C} 1$ to $\mathrm{MIC} \mathrm{C} 2$ or from $\mathrm{MIC} \mathrm{C} 2$ to $\mathrm{MIC} \mathrm{C} 3$ (MIC condition).

When the observer first conducted a study on the MIC classification, another researcher trained the observer in using the MIC classification. One hundred randomly selected panoramic radiographs were reanalyzed within at least 1.5 months between observations. The kappa values for intra- and interobserver agreement were 0.82 and 0.72 , respectively. Based on the guidelines of the interpretation of kappa statistics performed by Landis and Koch [16], the kappa values for intra- and interobserver agreement were in the categories of "almost perfect" and "substantial," respectively. The observer was one of the authors. 
To calculate the BMI, we used the subjects' heights and weights measured to the nearest $1 \mathrm{~mm}$ and $0.1 \mathrm{~kg}$, respectively. The BMI was calculated as weight $(\mathrm{kg})$ and divided by the square of the patient's height $\left(\mathrm{m}^{2}\right)$.

To obtain subjects' data on gender, smoking habit (SH), and current health status (CHS), we used the Tokyo Metropolitan Institute of Gerontology Index of Competence (TMIG-IC) subscale questionnaire. This questionnaire is used to assess functional capacity in older patients. The ability to perform a given function is indicated by an answer of "yes" or "no." The highest score on the TMIG-IC subscale is 13 points [17]; the mean score on this subscale of the subjects in this study was $11.9 \pm 1.4$ points. This assessment pointed to a high level of competency among the study participants.

Data Analysis

Statistical analysis of the MIC condition took place over nine years, and the BMI at baseline was evaluated using Student's t-test. Logistic regression analysis was performed to assess the relationship between the MIC condition over nine years and the BMI at baseline. The MIC condition was set as the dependent variable (O: those whose MIC classification did not change during the nine-year study period, 1: those whose MIC classification changed during the nine-year study period), whereas the BMI at baseline $\left(\mathrm{kg} / \mathrm{m}^{2}\right)$, gender (O: male, 1: female), SH at baseline (O: never smoked, 1: past or current smoking), and CHS at baseline (O: not good, 1: normal or feeling good) were set as the independent variables. The level of significance was set at p $<0.05$ for these tests. All calculations and statistical analyses were performed using the STATA software (StataCorp LLC, College Station, TX, USA).

\section{Results}

Significant differences between males and females were observed in the MIC condition $(\mathrm{p}<0.005)$, smoking habits $(\mathrm{p}<0.001)$, and current health status $(\mathrm{p}<0.05)$. On the other hand, no significant differences in the Body Mass Index at baseline were found between the two genders (Table 1).

Table 1. Distribution of participants according to MIC classification, BMI, smoking habit and health status.

\begin{tabular}{|c|c|c|c|}
\hline \multirow[b]{2}{*}{ Variables } & \multicolumn{2}{|c|}{ Gender } & \multirow[b]{2}{*}{ p-value } \\
\hline & $\begin{array}{c}\text { Male } \\
\mathrm{N}\end{array}$ & $\begin{array}{c}\text { Female } \\
\mathrm{N}\end{array}$ & \\
\hline \multicolumn{4}{|c|}{ Mandibular Inferior Cortex Classification } \\
\hline No Change & 108 & 82 & $<0.005^{*}$ \\
\hline Change & 28 & 48 & \\
\hline Body Mass Index at Baseline & $22.5 \pm 2.2$ & $22.5 \pm 2.7$ & $>0.05^{\#}$ \\
\hline \multicolumn{4}{|l|}{ Smoking Habit } \\
\hline No & 86 & 129 & $<0.001^{*}$ \\
\hline Yes & 50 & 1 & \\
\hline Current Health Status & & & $<0.05^{*}$ \\
\hline Not Good & 51 & 31 & \\
\hline Normal & 78 & 86 & \\
\hline Good & 7 & 13 & \\
\hline
\end{tabular}

The measurement of the MIC classification is shown in Table 2. C1, C2, and C3 in 1998 and 2007 were 127 (93.4\%), 9 (6.6\%), o (0\%), 99 (72.8\%), 37 (27.2\%), and o (0.0\%) for males and 68 (52.3\%), 62 (47.7\%), o (0.0\%), 27 (20.8\%), 96 (73.8\%), and 7 (5.4\%) for females, respectively. The percentages of MIC classification $\mathrm{C} 1$ 
were decreased, whereas the percentages of MIC classification C2 were increased in both males and females during the nine-year study period. MIC C3 was only found in female subjects during the final year. Subjects whose MIC classification changed from $\mathrm{C}_{1}$ to $\mathrm{C} 2$ or from $\mathrm{C} 2$ to $\mathrm{C} 3$ were $20.6 \%$ for males and $36.9 \%$ for females. We found significant differences in the distribution of MIC classifications between 1998 and 2007 among both males and females $(\mathrm{p}>0.05)$.

Table 2. Distribution of the MIC classification in male and female subjects.

\begin{tabular}{|c|c|c|c|c|c|}
\hline & $\mathbf{M}_{\mathbf{z}}$ & Ir Inferior & x Classif & & \\
\hline Gender & $\mathrm{C} 1^{*}$ & $\mathrm{C} 2^{* *}$ & $\mathrm{C} 3^{* * * *}$ & Total & p-value \\
\hline & $\mathrm{N}(\%)$ & $\mathrm{N}(\%)$ & $\mathrm{N}(\%)$ & $\mathrm{N}(\%)$ & \\
\hline Males & & & & & \\
\hline $\mathrm{C} 1^{*}$ & $99(77.9)$ & $28(22.1)$ & $0(0.0)$ & $127(93.4)$ & $<0.001^{\#}$ \\
\hline $\mathrm{C} 2^{* * *}$ & $\mathrm{O}(0.0)$ & $9(100.0)$ & $0(0.0)$ & $9(6.6)$ & \\
\hline $\mathrm{C} 3^{* * *}$ & $\mathrm{O}(0.0)$ & $\mathrm{O}(0.0)$ & $0(0.0)$ & $\mathrm{O}(0.0)$ & \\
\hline Total & $99(72.8)$ & $37(27.2)$ & $0(0.0)$ & $136(100.0)$ & \\
\hline Females & & & & & $<0.001^{\#}$ \\
\hline $\mathrm{C} 1^{*}$ & 27 & 41 & $0(0.0)$ & $68(52.3)$ & \\
\hline $\mathrm{C} 2^{* *}$ & $\mathrm{O}(0.0)$ & $55(88.7)$ & $7(11.3)$ & $62(47.7)$ & \\
\hline $\mathrm{C} 3^{* * * *}$ & $\mathrm{O}(0.0)$ & $\mathrm{O}(0.0)$ & $\mathrm{O}(0.0)$ & $\mathrm{O}(0.0)$ & \\
\hline Total & $27(20.8)$ & $96(73.8)$ & $7(5.4)$ & $130(100.0)$ & \\
\hline
\end{tabular}

The mean and standard deviation values for the BMI at baseline in those whose MIC classification did not change and those whose MIC classification did change during the nine-year study period were $22.8 \pm 2.1$ and $21.8 \pm 2.5 \mathrm{~kg} / \mathrm{m}^{2}$ for males and $23.1 \pm 2.9$ and $21.9 \pm 2.4 \mathrm{~kg} / \mathrm{m}^{2}$ for females, respectively (Figure 2). The mean values of the BMI at baseline were significantly higher among males $(p=0.04)$ and females $(p=0.01)$ in the group whose MIC grade did not change for nine years compared to the group whose grade increased.
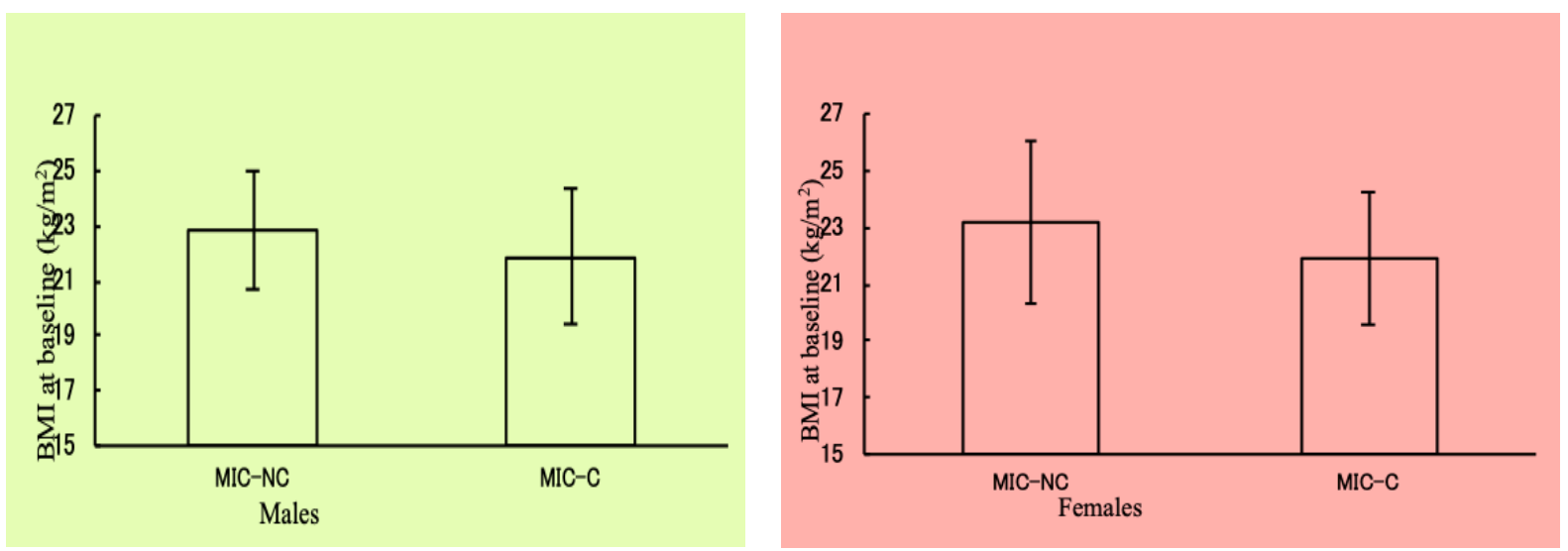

Figure 2. Mean body mass index (BMI) score at baseline for males and females by group according to no change or change in the MIC condition.

The results of the logistic regression analysis are shown in Table 3. The baseline was lower in the group whose MIC grade remained unchanged. The results showed that a higher BMI at baseline $(\mathrm{OR}=0.84$, $\mathrm{p}=0.003)$ was strongly correlated with protective measures against a change in MIC over the nine-year study, after it was adjusted for gender $(\mathrm{OR}=5.18, \mathrm{p}=0.000)$, current health status $(\mathrm{OR}=0.53, \mathrm{p}=0.015)$, and smoking habit $(\mathrm{OR}=4.15, \mathrm{p}=0.002)$ at baseline. 
Table 3. Results of the logistic regression analysis using the MIC condition as a dependent variable.

\begin{tabular}{lcccc}
\multicolumn{1}{c}{$\begin{array}{c}\text { Mandibular Inferior Cortex } \\
\text { Classification }\end{array}$} & Odds Ratio & Standard Error & $\mathbf{9 5 \%}$ CI & p-value \\
\hline Body Mass Index at Baseline & 0.84 & 0.05 & $0.75-0.94$ & 0.003 \\
Gender & 5.18 & 2.04 & $2.4-1.20$ & 0.000 \\
Smoking Habit & 4.15 & 1.87 & $1.72-10.05$ & 0.002 \\
Current Health Status & 0.53 & 0.14 & $0.31-0.88$ & 0.015 \\
$\quad$ Pseudo-R ${ }^{2}$ & & & & 0.116 \\
\hline
\end{tabular}

\section{Discussion}

This is the first longitudinal study investigating the relationship between the BMI at baseline and mandibular bone porosity by measuring the MIC condition. This study demonstrates that the BMI at baseline is significantly associated with mandibular bone porosity (Figure 2). Subjects with a lower BMI at baseline exhibited MIC changes trending toward porosity more significantly than those with a higher BMI. These results are concordant with previous cross-sectional studies showing that obese people have higher mandibular BMD than nonobese people [6]. Some investigators explained that this occurs because of a gravitational effect caused by increased body weight [18] or because obese individuals have a heavier skeleton and a larger amount of fat in their bodies and are less predisposed to osteoporosis compared to nonobese individuals [19]. Therefore, this nine-year cohort study suggests that a lower BMI at baseline is one of the risk factors for mandibular bone porosity progression upon measuring the MIC condition in panoramic radiographs.

There were no significant differences between males and females in terms of BMI at baseline (Table 1), but we found that the distribution of MIC classifications at baseline in males was dominated with $\mathrm{C} 1$ (normal cortex), whereas in females, MIC C1 and $\mathrm{C} 2$ had slightly different prevalence rates. Furthermore, subjects whose MIC classifications changed from $\mathrm{C} 1$ after nine years were more often female than male (Table 2). In addition, logistic regression analysis confirmed that females were at a higher risk for a change in the MIC. These results are in accordance with other reports suggesting that fractures' overall prevalence is higher in females than in males [13,20]. Regarding the MIC classification, some investigators reported significant differences in MIC results between both genders [13,14], consistent with this study's results.

The logistic regression analysis results showed that a higher BMI at baseline was correlated with a change in the MIC over the nine-year study period. Furthermore, the results showed that subjects whose MIC classification changed were 5.18 times more likely to be females than males. Conversely, subjects with a past or current SH were 4.15 times more likely to have a changed MIC classification relative to subjects who did not smoke. Smoking is known to be a risk factor for osteoporosis [21]. However, some researchers reported no strong evidence or a negative correlation between cigarette smoking and BMD measurements of the mandible [22]. We herein reported a positive correlation between $\mathrm{SH}$ and mandibular bone porosity after nine years of study. These findings might be considered a reminder of the long-term dangers of smoking on health in elderly people.

These findings have important implications from a public health point of view. Our study was conducted on mandibular bone, and even though the association between BMI and osteoporosis has been studied [23], this study was still necessary because DEXA is used as a gold standard for diagnosing osteoporosis. In elderly people, a higher BMI is more likely to protect against acute injury from traumatic events, such as falls. There are lower osteoporosis rates in obese individuals, resulting from fatty tissue synthesis of estrogens and greater weight-bearing-related bone formation. Furthermore, elderly people with higher BMI values are more likely to have a better nutritional status and functional capabilities [24]. 
Given that several investigators have reported the benefits of a higher BMI in elderly people, lowerBMI groups should, therefore, be a clinical target population in whom to address bone loss. Research has shown that a low BMI is associated with mortality even when controlling for a wide variety of measures, such as baseline illness, including short-term unintended weight loss [25]. For dentists who have a series of panoramic radiographs, if they observe the condition of the mandibular bone in the elderly as porous, especially if evolving from MIC C2 to MIC C3 (i.e., MIC condition change), such can be used as a consideration in the management of selected patients, especially related to systemic osteoporosis. Furthermore, if that patient is female or has other risk factors of osteoporosis, such as smoking and/or a BMI lower than $21.8 \pm 2.5 \mathrm{~kg} / \mathrm{m}^{2}$ for males or $21.9 \pm 2.4 \mathrm{~kg} / \mathrm{m}^{2}$ for females, we should refer these patients to a medical professional to undergo an examination of osteoporosis in order to prevent fractures related to this condition.

This study has several limitations that need to be taken into consideration. All subjects were in good general health and had a high TMIG-IC score. Our sample could have been biased by the exclusion of subjects who did not meet these criteria. Data on exercise activities and history of medication use were also not available. This may limit the interpretation of our findings. Further studies that consider these factors are needed.

\section{Conclusion}

A low body mass index is a risk factor for developing mandibular bone porosity by measuring the mandibular inferior cortex condition in panoramic radiographs.

\section{Authors' Contributions}

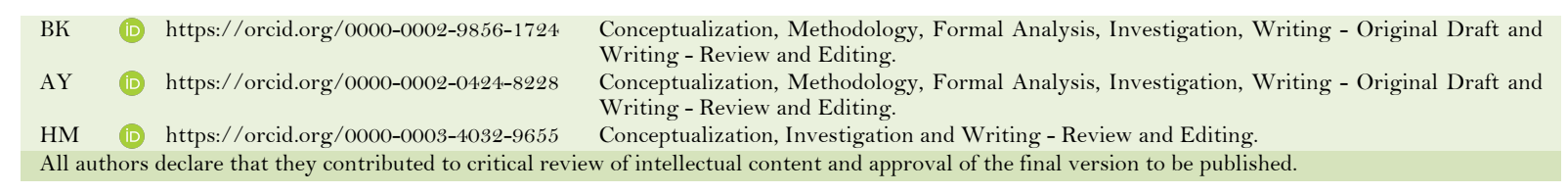

\section{Financial Support}

This work was supported by Grants-in-Aid from the Japan Society for the Promotion of Science (No.17592 177) and the Ministry of Health and Welfare of Japan (H10-Iryo-001) and by the Directorate of Research and Community Service, University of Indonesia, from grant PUTI Q3 (Penelitian Unggulan Perguruan tinggi) 2020, contract number: NKB-1918/UN2.RST/HKP.05.00/2020.

\section{Conflict of Interest}

The authors declare no conflicts of interest.

\section{Data Availability}

The data used to support the findings of this study can be made available upon request to the corresponding author.

\section{References}

[1] Sözen T, Özışık L, Başaran NÇ. An overview and management of osteoporosis. Eur J Rheumatol 2017; 4(1):46-56. https://doi.org/10.5152/eurjrheum.2016.048

[2] Hernlund E, Svedbom A, Ivergård M, Compston J, Cooper C, Stenmark J, et al. Osteoporosis in the European Union: medical management, epidemiology and economic burden. A report prepared in collaboration with the International Osteoporosis Foundation and the European Federation of Pharmaceutical Industry Associations (EFPIA). Arch Osteoporos 2013; 8(1-2):136. https://doi.org/10.1007/s11657-013-0136-1

[3] Fraser L, Loannidis G, Adachi JD, Pickard L, Kaiser SM, Prior J, et al. Fragility fractures and the osteoporosis care gap in women: The Canadian multicentre osteoporosis study. Osteoporos Int 2011; 22(3):789-96. https://doi.org/10.1007/s00198-010-1359-2 
[4] Jaglal SB, Donescu OS, Bansod V, Laprade J, Thorpe K, Hawker G, et al. Impact of a centralized osteoporosis coordinator on post-fracture osteoporosis management: a cluster randomized trial. Osteoporos Int 2012; 23(1):87-95. https://doi.org/10.1007/s00198-011-1726-7

[5] Shapses SA, Pop CL, Wang Y. Obesity is a concern for bone health with aging. Nutr Res 2017; 39:1-13. https://doi.org/10.1016/j.nutres.2016.12.010

[6] Caffarelli C, Alessi C, Nuti R, Gonnelli S. Divergent effects of obesity on fragility fractures. Clin Interv Aging 2014; 9:1629-36. https://doi.org/10.2147/CIA.S64625

[7] Petrie JR, Guzik TJ, Touyz RM. Diabetes, hypertension, and cardiovascular disease: Clinical insights and vascular mechanisms. Can J Cardiol 2018; 34(5):575-84. https://doi.org/10.1016/j.cjca.2017.12.005

[8] AlGhatrif M, Kuo Y, Snih SA, Raji MA, Ray LA, Markides KS. Trends in hypertension prevalence, awareness, treatment and control in older Mexican Americans, 1993-2005. Ann Epidemiol 2011; 21(1):15-25. https://doi.org/10.1016/j.annepidem.2010.06.002

[9] Zlatarić DK, Celebić A, Kobler P. Relationship between body mass index quality of mandibular bone structure in elderly individuals. J Gerontol A Biol Sci Med Sci 2002; 57(9):M588-93. https://doi.org/10.1093/gerona/57.9.m588

[10] Klemetti E, Kolmakov S, Kröger H. Pantomography in assessment of the osteoporosis risk group. Scand J Dent Res 1994; 102(1):68-72. https://doi.org/10.1111/j.1600-0722.1994.tbo1156.x

[11] Lee K, Taguchi A, Ishii K, Suei Y, Fujita M, Nakamoto T, et al. Visual assessment of the mandibular cortex on panoramic radiographs to identify postmenopausal women with low bone mineral densities. Oral Surg Oral Med Oral Pathol Oral Radiol Endod 2005; 100(2):226-31. https://doi.org/10.1016/j.tripleo.2004.11.052

[12] Taguchi A, Tsuda M, Ohtsuka M, Kodama I, Sanada M, Nakamoto T, et al. Use of dental panoramic radiographs in identifying younger postmenopausal women with osteoporosis. Osteoporos Int 2006; 17(3):387-94. https://doi.org/10.1007/s00198-005-2029-7

[13] Kiswanjaya B, Yohihara A, Deguchi T, Hanada N, Miyazaki H. Relationship between the mandibular inferior cortex and bone stiffness in elderly Japanese people. Osteoporos Int 2010; $21(3): 433-8$.

https://doi.org/ 10.1007/s00198-009-0996-9

[14] Kiswanjaya B, Yoshihara A, Miyazaki H. Mandibular inferior cortex erosion as a sign of elevated total serum calcium in elderly people: A 9-year follow-up study. Dentomaxillofac Radiol 2014; 43(3):20130341. https://doi.org/10.1259/dmfr.20130341

[15] Deguchi T, Yoshihara A, Hanada N, Miyazaki H. Relationship between mandibular inferior cortex and general bone metabolism in older adults. Osteoporos Int 2008; 19(7):935-40. https://doi.org/10.1007/s00198-007-0526-6

[16] Landis JR, Koch GG. The measurement of observer agreement for categorical data. Biometrics 1977; 33(1):159-74.

[17] Iwasa H, Masui Y, Inagaki H, Yoshida Y, Shimada H, Otsuka R, et al. Development of the Japan science and technology agency index of competence to assess functional capacity in older adults. Gerontol Geriatr Med 2015; 1:2333721415609490. https://doi.org/10.1177/2333721415609490

[18] Daly RM, Via JD, Duckham RL, Fraser SF, Helge EW. Exercise for the prevention of Osteoporosis in postmenopausal women: an evidence-based guide to the optimal prescription. Braz J Phys Ther 2019; 23(2):170-80. https://doi.org/10.1016/j.bjpt.2018.11.011

[19] Cao JJ. Effects of obesity on bone metabolism. J Orthop Surg Res 2011; 6:30. https://doi.org/10.1186/1749-799X-6-30

[20] Alswat KA. Gender disparities in osteoporosis. J Clin Med Res 2017; 9(5):382-7. https://doi.org/10.14740/jocmr2970w

[21] Lane NE. Epidemiology, etiology, and diagnosis of osteoporosis. Am J Obstet Gynecol 2006; 194(2 Suppl):S3-11. https://doi.org/10.1016/j.ajog.2005.08.047

[22] Drage NA, Palmer RM, Blake G, Wilson R, Crane F, Fogelman I. A comparison of bone mineral density in the spine, hip and jaws of edentulous subjects. Clin Oral Implants Res 2007; 18(4):496-500.

https://doi.org/10.1111/j.1600-0501.2007.01379.x

[23] Mazocco L, Chagas P. Association between body mass index and osteoporosis in women from northwestern Rio Grande do Sul. Rev Bras Reumatol 2017; 57(4):299-305. https://doi.org/10.1016/j.rbre.2016.10.002

[24] Luger E, Haider S, Kapan A, Schindler K, Lackinger C, Dorner TE. Association between nutritional status and quality of life in (pre) frail community-dwelling older persons. J Frailty Aging 2016; 5(3):141-8.

[25] Klenk J, Rapp K, Ulmer H, Concin H, Nagel G. Changes of body mass index in relations to mortality: Results of a cohort of 42.099 adults. PLoS One 2014; 9(1):e84817. https://doi.org/10.1371/journal.pone.0084817 